\title{
¿Por qué son importantes los Estudios Feministas?
}

Soraia Carolina de Mello, Universidade do Estado de Santa Catarina

Tradução: Yarlenis Ileinis Mestre MALFRÁN, UFSC

Revisão: Matilde Quiroga CASTELLANO, UFSC

\section{Referência Original:}

MELLO, Soraia Carolina de. Por que os Estudos Feministas são importantes? 2019. Dis ponível e m: < https:// www.cafehistoria.com.br/por-que-os-estudos-feministas-saoimportantes/>. Acesso em: o1 ago. 2019.

Este artículo de divulgación científica busca responder, de forma didáctica y accesible, a la pregunta acerca de por qué son importantes los estudios feministas. La argumentación fue construida en tres partes: la primera trata de la invisibilidad de determinados sujetos en las ciencias, como objeto de estudio $\mathrm{y}$, principalmente, como productores de conocimiento; la segunda trata de la negación del prejuicio y de la discriminación contra esos sujetos; y la tercera trata de las posibilidades de transformación de ese marco. El foco son las mujeres (incluidas las trans), consideradas como el sujeto de los feminismos, y a pesar de ser un diálogo profundamente interdisciplinario, fue escrito a partir del lugar de la Historia como área de conocimiento.

PALABRAS Clave: Estudios Feministas. Epistemologías feministas. Posicionalidad. Desigualdad de género. Decolonialidad. 
Me gustaría dividir este trabajo en tres partes: la primera trata de la invisibilidad de determinados sujetos en las ciencias, como objetos de estudio $\mathrm{y}$, principalmente, como productores de conocimiento; la segunda trata de la negación del prejuicio y de la discriminación contra esos sujetos; y la tercera trata de las posibilidades de transformación de este marco. El foco son las mujeres (incluidas las trans), consideradas como el sujeto de los feminismos (COSTA, 2002).

La invisibilidad se refiere al supuesto universalismo de las ciencias, que alegan ser neutras. No obstante, los estudios feministas, así como los saberes negros, indígenas, sobre deficiencias, LGBTQ+ y decoloniales ${ }^{1}$, ya percibieron que las ciencias no son neutras. Ellas son producidas a partir de determinada perspectiva, que está relacionada con la posicionalidad del sujeto que produce ciencia. Tradicionalmente este sujeto era el sujeto del colonialismo, el colonizador: el hombre blanco (europeo o descendiente de este), perteneciente por regla general a clases sociales privilegiadas - es decir, el sujeto hegemónico. Nunca era el/la colonizado/a, ni las mujeres. El androcentrismo, en este contexto, puede definirse como la práctica de considerar la experiencia de los hombres como universal, como válida para toda la humanidad, incluyendo las mujeres, que son más de la mitad de la población mundial y que han vivido históricamente de maneras muy diferentes a las de los hombres.

Ahora bien, ¿Qué cambia cuando se consideran estas cuestiones? ¿Son suficientes la verificación científica y las evidencias suficientes para probar la neutralidad de las ciencias? Los estudios feministas argumentan que no, sino que dependiendo quién es el sujeto del conocimiento, quién lo produce, el saber se transforma. Desde esta perspectiva los conocimientos son siempre situados y, por lo tanto, inevitablemente parciales (HARAWAY, 1995).

El conocimiento se produce a partir de preguntas, y la posicionalidad del sujeto cambia radicalmente esas preguntas. Por tal razón, cuando las herramientas teóricas androcéntricas no responden a

1 En una entrevista publicada en la Revista del Instituto Humanitas Unisinos, Luciana Ballestrin explica que la expresión (...) decolonial no debe ser confundida como mera descolonización. "En términos históricos y temporales, esta última indica una superación del colonialismo; por su parte, la idea de decolonialidad (o descolonialidad) busca trascender la colonialidad, la cara oscura de la modernidad, que sigue operando hasta los días actuales como un patrón mundial de poder. (...) El giro decolonial busca responder a las lógicas de la colonialidad del poder, ser y saber, apostando a otras experiencias políticas, vivencias culturales, alternativas económicas y producción del conocimiento". 
nuestras preguntas, elaboramos nuevas herramientas teóricas. El concepto de género, o el de cuir (o queer ${ }^{2}$, si así lo prefieren), son excelentes ejemplos de herramientas teóricas desarrolladas por sujetos que se sintieron insatisfechos con las herramientas teóricas de las ciencias androcéntricas, ya que éstas no respondían de forma adecuada o de manera suficiente a sus preguntas. Es decir, los conceptos utilizados para explicar las relaciones sociales basadas en la clase, no eran suficientes, por sí solos, para explicar de forma satisfactoria otras matrices de desigualdad, exclusión y explotación, que inclusive se han impuesto sobre las mujeres.

Negar que existen otras matrices de desigualdad, o afirmar que ellas son secundarias con relación a una matriz principal, es negar también las formas de exclusión y discriminación específicas. Asumir que la superación de las desigualdades de clase resultará también en una superación de las desigualdades entre hombres y mujeres, de la discriminación racial y de la homofobia (por citar algunos ejemplos), es una manera frecuente de invisibilizar las especificidades de determinadas desigualdades. A pesar de una serie de estudios que reflexionan sobre la interseccionalidad de las categorías, queda demostrado que las relaciones de exclusión y explotación no son nada simples.

Cabe destacar que cuando hablamos de especificidad, no nos estamos refiriendo a una relación numérica, que involucra a una minoría de personas. La mayor parte de la población mundial está compuesta por mujeres. Son tantas mujeres que sus experiencias difieren entre sí profundamente, y por ello usamos el plural en lugar de hablar de mujer en singular. Por estas mismas razones, los estudios feministas están cada

2 Concepto complejo que busca superar la heteronormatividad y el binarismo de género, para lo cual apela a los conceptos de extraño y monstruosidad. Su uso político está relacionado con la superación de la constitución identitaria como condición de legitimidad de determinadas prácticas sociales, culturales y sexuales, y de las fronteras establecidas a partir de esas prácticas. Por ejemplo, la exigencia de tener vagina para ser considerada una mujer; o no poder autoidentificarse como un hombre heterosexual y cisgénero con un pene y al mismo tiempo vestirse todos los días con ropas entendidas socialmente como femeninas. Dentro de la teoría queer esas prácticas no son naturalizadas, estas fronteras se entienden como artificiales y como mecanismos que crean y fortalecen jerarquías. El concepto es objeto de disputas y críticas tanto en la academia cuanto en los movimientos sociales. Algunas lecturas sobre la cuestión: PRECIADO, Beatriz. Multidões queer: notas para uma política dos "anormais". Revista Estudos Feministas, Florianópolis, v. 19, n. 1, pp. 11-20, jan. 2011; MOMBAÇA, Jota. Para desaprender o queer dos trópicos: desmontando a caravela queer. [SEXX BBOX], 28/o8/2016; e BAKER, Meg-John, SCHEELE, Julia. Queer - a graphic history. London: Icon Books, 2016. 
vez más preocupados en relación a las interseccionalidades, es decir, sobre el entrecruzamiento de diferentes categorías de exclusión (GONZÁLEZ, 1984) que una vez tenidas en cuenta, posibilitan pensar sobre esas diferentes mujeres.

Como la academia no es un espacio neutro (KILOMBA, 2010), las mujeres, así como otros sujetos subalternizadas, son entendidas como específicas, como lo otro. El término "segundo sexo", título del famoso libro de Simone de Beauvoir, proviene de esa relación con lo que se entiende como universal. Tradicionalmente, las Ciencias Sociales no han abordado las experiencias de los hombres considerándolas como específicas con relación a las de las mujeres. La especificidad ha sido siempre ubicada en el "otro". Ese otro entonces es inequívocamente secundario. Un efecto derivado de ese modo de pensar la relación entre el sujeto hegemónico y ese otro, ha sido la naturalización de la desigualdad, la falta de equidad y la falta de acceso a derechos iguales en el discurso de las ciencias. De igual manera, el prejuicio y la discriminación se convierten en "invenciones". Los estudios feministas ofrecen una contra narrativa a esa perspectiva de ciencia "neutra" que invisibiliza las desigualdades.

Pero ¿cuál sería, al final, la utilidad de los estudios feministas en nuestras sociedades pragmáticas? ¿Qué resultados ofrecen estos estudios para la vida práctica de las personas? Las ciencias pueden parecer distantes de lo cotidiano, no obstante, evidenciar las desigualdades se constituye en un prerrequisito fundamental para pensar y construir las transformaciones. ¿Cómo vamos a combatir el femicidio si negamos su existencia? ¿Cómo reivindicar una distribución de salario más equitativa entre hombres y mujeres si consideramos a estudios tales como los que abordan la feminización de la pobreza como parciales, específicos, desconectados de un contexto general, global?

Los movimientos sociales, sus articulaciones y sus luchas, las iniciativas individuales y colectivas, las políticas públicas a favor de la igualdad de género que también han llevado a cabo debates sobre sexualidad y, a través de diferentes frentes, han transformado las vidas de las personas - y salvado tantas otras - y sólo pueden ser específicos desde la perspectiva de los sujetos hegemónicos. Al final de cuentas, es para eso que sirven los estudios feministas, para transformar y salvar vidas, para erradicar escandalosas e históricas injusticias sociales. 
Cuando producimos conocimiento a partir de un determinado punto de vista - desde una posición no masculina, no hegemónica, preocupada por la superación de las desigualdades, es decir, feminista, política - realizamos dos movimientos. El primero de ellos resulta en un enriquecimiento de las ciencias como un todo, incluso las hegemónicas, androcéntricas, coloniales, ya que desde perspectivas diversas, plurales, basadas en la proliferación de datos, sujetos, teorías, investigaciones y enfoques, la producción de conocimiento siempre se amplía. El segundo movimiento es aquel que trae consigo la afirmación de la existencia de sujetos que anteriormente eran negados o condenados a guetos específicos. Consecuentemente, estos sujetos que eran objeto de análisis pasan a ser también productores de conocimiento, en un contexto en el que un enfoque no androcéntrico sobre la sociedad (porque los estudios feministas no estudian sólo mujeres), favorece la complejidad de la producción científica.

Lo que se exige al final es verosimilitud con la producción científica realizada por y sobre hombres (aquella que no es nombrada como específica porque es entendida como universal). Pensando específicamente en la Historia como disciplina, los estudios feministas anhelan que la historiografía sobre mujeres sea tan rica y compleja como aquella sobre hombres. Ello significa posibilitar que sujetos estigmatizados, usurpados de poder, libertad y autonomía debido las jerarquías de género (incluidas aquí las poblaciones LGBTQ+) tengan el mismo acceso a la producción del conocimiento, el mismo derecho a la historia, a la memoria, a la identidad y a la noción de pertenencia que el que poseen los hombres blancos, heterosexuales y cisgéneros en las ciencias y, específicamente, en la historia.

\section{Referências}

BAKER, Meg-John, SCHEELE, Julia. Queer - a graphic history. London: Icon Books, 2016.

BEAUVOIR, Simone de. O Segundo Sexo: Fatos e Mitos. Volume 1. Rio de Janeiro: Nova Fronteira, 1970.

COSTA, Claudia de Lima. O sujeito no feminismo: revisitando os debates. Cadernos Pagu, Campinas, n. 19, pp. 59-90, 2002. 
GONZALEZ, Lélia. Racismo e sexismo na cultura brasileira. Ciências Sociais Hoje, São Paulo, Anpocs, pp. 223-244, 1984.

HARAWAY, Donna. Saberes localizados: a questão da ciência para o feminismo e o privilégio da perspectiva parcial. Cadernos Pagu, n. 5, pp. 07-42, 1995 .

KILOMBA, Grada. Who can speak? In: KILOMBA, Grada. Plantation memories. Münster: Unrast Verlag, 2010.

MOMBAÇA, Jota. Para desaprender o queer dos trópicos: desmontando a caravela queer. [SEXX BBOX], 28/o8/2016.

PRECIADO, Beatriz. Multidões queer: notas para uma política dos "anormais". Revista Estudos Feministas. Florianópolis, v. 19, n. 1, pp. 11-20, jan. 2011. 


\section{Por que os Estudos Feministas são importantes?}

RESUMO: Este artigo de divulgação científica busca responder, de forma didática e acessível, por que os estudos feministas são importantes. A argumentação foi construída em três partes: a primeira trata da invisibilidade de determinados sujeitos nas ciências, como objeto de estudo e, principalmente, como produtores de conhecimento; a segunda trata da negação do preconceito e da discriminação contra esses sujeitos; e a terceira trata das possibilidades de transformação desse quadro. $\mathrm{O}$ foco são as mulheres (inclusas as trans), o sujeito dos feminismos e, apesar de ser um diálogo profundamente interdisciplinar, foi escrito a partir do lugar da História como área de conhecimento.

PALAVRAS-CHAVE: Estudos Feministas. Espistemologias feministas. Posicionalidade do sujeito. Desigualdade de gênero. Decolonialidade.

\section{Soraia Carolina de Mello}

Licenciada e bacharel em História, Doutora em História Cultural pela Universidade Federal de Santa Catarina (UFSC). Professora da Universidade do Estado de Santa Catarina (UDESC), contribui com as equipes do Laboratório de Estudos de Gênero e História (LEGH) e do Instituto de Estudos de Gênero (IEG) da UFSC desde 2005. Editora de artigos da Revista Estudos Feministas desde 2017.

\section{Yarlenis Ileinis Mestre Malfrán}

Doutoranda no Programa de Pós-Graduação Interdisciplinar em Ciências Humanas da Universidade Federal da Santa Catarina, Bolsista CAPES PEC-PG. Possui graduação em Psicologia pela Universidade de Oriente, Santiago de Cuba (1999), mestrado em Intervenção Comunitária pelo Instituto Superior de Ciências Médicas Habana/Cuba (2004). Atualmente pesquisa políticas públicas de saúde em Cuba a partir de uma abordagem interseccional. Bolsista PEC-PG/CAPES

(2017-2021).

Matilde Quiroga Castellano

Doutoranda em Antropologia Social (PPGAS- UFSC) com bolsa CAPES, Mestra em Antropologia Social pela Universidade Federal de Santa Catarina.

Formada em "Licenciatura en Trabajo Social" pela Universidad Nacional de Córdoba, Argentina. Atuou profissionalmente na assistência e prevenção de vítimas de tráfico de pessoas, na "Secretaria de Asistencia y Prevención de la Trata de Personas", do "Ministerio de Gobierno y Seguridad" da Provincia de Córdoba, Argentina. Pesquisadora do LEVIS (Laboratório (Núcleo) de Estudos das Violências). 